\title{
Treatment of critically ill children with kidney injury by sustained low-efficiency daily diafiltration
}

\author{
Chia-Ying Lee $\cdot$ Huang-Chieh Yeh $\cdot$ Ching-Yuang Lin
}

Received: 16 August 2011 /Revised: 9 June 2012 / Accepted: 11 June 2012 /Published online: 18 August 2012

(C) The Author(s) 2012. This article is published with open access at Springerlink.com

\begin{abstract}
Background Continuous renal replacement therapy (CRRT) and intermittent hemodialysis (IHD) offer diverse benefits and drawbacks for critically ill children with acute kidney injury (AKI). Sustained low-efficiency daily diafiltration (SLEDD-f) involves a conceptual and technical hybrid of CRRT and IHD. We report our SLEDD-f application to critically ill children in the pediatric intensive care unit (PICU).

Methods SLEDD-f was delivered by the new Fresenius 5008 therapy system with blood flow $5 \mathrm{ml} / \mathrm{kg} / \mathrm{min}$, dialysate flow $260 \mathrm{ml} / \mathrm{min}$, hemofiltration $35 \mathrm{ml} / \mathrm{kg} / \mathrm{h}$ for $8-10 \mathrm{~h}$ daily. Changes in blood pressure, blood gas, electrolyte, hemoglobulin $(\mathrm{Hb})$, and hematocrit (Hct) were closely monitored.

Results From February 2010 to June 2011, 14 critical patients with a total of 60 SLEDD-f sessions were studied retrospectively. Heparin was used in 46 sessions $(76.6 \%)$ with no bleeding complications. Hypertension above $135 \mathrm{mmHg}$ returned to normal, hypotension below $90 \mathrm{mmHg}$ showed
\end{abstract}

C.-Y. Lee $\cdot$ C.-Y. Lin

Division of Pediatric Nephrology, Children's Medical Center, China Medical University Hospital, China Medical University, Taichung, Taiwan

H.-C. Yeh

Division of Nephrology, Department of Medicine, China Medical University and Hospital,

Taichung, Taiwan

C.-Y. Lin $(\bowtie)$

College of Medicine, China Medical University,

No.2, Yuh-Der Rd.,

Taichung 40402, Taiwan

e-mail: cylin@mail.cmuh.org.tw

C.-Y. Lin

Clinical Immunology Center,

China Medical University Hospital,

No.2, Yuh-Der Road,

Taichung 40402, Taiwan no drop. Metabolic acidosis and hyperkalemia normalized. Elevated $\mathrm{Hb}$, Hct, and their ratio revealed improving hemodilution. Three episodes of intradialytic hypotension (5.0\%) and one of circuit clotting $(1.7 \%)$ led to premature termination. The 28 -day survival rate was $71.4 \%$.

Conclusions This pilot investigation demonstrates that SLEDD-f provides good hemodynamic tolerance and correction of fluid overload, $\mathrm{pH}$, and electrolyte imbalance for critically ill children with AKI.

Keywords Acute kidney injury · Continuous renal replacement therapy $\cdot$ Intermittent hemodialysis $\cdot$ Sustained low efficiency daily diafiltration · Critically ill children

\section{Introduction}

Two classic options for acute kidney injury (AKI) are intermittent hemodialysis (IHD) and continuous renal replacement therapies (CRRT), each with benefits and drawbacks. IHD is applied with the diffusion principle and performed for around $4 \mathrm{~h}$ per session every other day. CRRT with convection only or combined diffusion is performed nonstop. The superior modality for AKI in adults remains controversial [1], but CRRT has seen widest use in children with critical AKI because of continuous programmed fluid removal plus better hemodynamic tolerance [2-4]. Yet CRRT frequently gives rise to complications in such cases: e.g. intradialytic hypotension, hemorrhage, electrolyte disturbance [5]. The ideal renal replacement for children should provide adequate hemodynamic stability, good volume control, solute removal, high efficacy in correcting acid-base abnormalities, and electrolyte imbalance. It should involve minimal work with limited cost, be nonlabor-intensive and/or technically demanding, provide dialysis-free time out of the pediatric intensive care unit (PICU) for diagnostic and therapeutic procedures while enhancing renal recovery and 
survival without complications $[1,6]$. IHD is not well tolerated owing to rapid fluid shift and poor quality of life during therapy. CRRT is better tolerated, yet complications and costeffectiveness pose problems, especially in resource-limited nations $[4,5]$. Sustained low-efficiency daily diafiltration (SLEDD-f), a conceptual and technical hybrid of IHD and CRRT, is an increasingly popular method of renal replacement for AKI patients [1,7]. Adult studies have yielded excellent clinical and metabolic outcomes in critically ill AKI patients [7, 8]. To our knowledge, no one has ever reported on SLEDD-f usage in children; we thought it worthwhile to share our experience and rate the clinical efficacy, quality of life, and cost analysis of SLEDD-f therapy in critically ill children with AKI.

\section{Materials and methods}

\section{Patients}

The progress records of 14 critical AKI patients from February 2010 to June 2011 with a total of 60 SLEDD-f sessions in PICU who met the criteria for RRT were retrospectively collected and reviewed. Children with body weight (BW) less than $20 \mathrm{~kg}$, brain death or severe neurological involvement were excluded. Because of a lack of proper hemodiafilters and tubing sets for SLEDD-f in children less than $20 \mathrm{~kg}$ in Taiwan, we preferred continuous veno-venous hemofiltration $(\mathrm{CVVH})$ for them, giving SLEDD-f top priority to larger children and adolescents. For brain death and severe neurological involvement, palliative care is considered first. We respect family opinions and suggestions from pediatric neurologists, detailing the advantages and disadvantages of RRT to them.

Data and clinical information included demographic characteristics (age, gender, and body weight), diagnosis, Pediatric Risk of Mortality III (PRISM III) score, percentage of fluid overload (\%FO), and outcome. Decisions on SLEDD-f were reached by both the attending intensivist and the nephrologist according to indications, such as elevated blood urea nitrogen (BUN) and serum creatinine ( $\mathrm{sCr}$ ), oliguria, acute volume overload or electrolyte imbalance refractory to other therapy. According to ambulatory blood pressure monitoring (ABPM) and reference values for ABPM in normal children and adolescents in Taiwan [9], we defined systolic blood pressure (sBP) above $135 \mathrm{mmHg}$ as hypertension and below $90 \mathrm{mmHg}$ as hypotension. Definitions of AKI and end-stage renal disease (ESRD) are based on pediatric-modified RIFLE criteria [10]. Multi-organ dysfunction syndrome (MODS) meant that the underlying primary disease leading to AKI affected at least one organ system other than the kidneys [11]. The percentage of fluid overload $(\% \mathrm{FO})$ was calculated as (fluid in - fluid out) $/$ (ICU admission weight $) \times 100 \%$ [12]. Technical information regarding SLEDD-f prescription included blood flow rate, dialysate flow rate, real duration, replacement fluid, ultrafiltration volume, heparin dose and complications. Vital signs, blood gas, electrolyte, and biochemistry data were closely monitored before, during, and after SLEDD-f therapy.

To evaluate the changes in inflammatory markers, we collected serum before and after SLEDD-f. Levels of adiponectin, IL-17A, and IL-6 were measured in duplicate by ELISA kits (Assay-Pro Inc., Brooklyn, NY, USA), as per the manufacturer's instructions.

A questionnaire was specifically designed for ESRD [13], dialysis [14], and modified quality of life evaluation [15, 16] and was applied in Taiwan with fair reliability (Cronbach's $\alpha$ between approximately 0.888 and 0.924 ) and validity (Pearson correlation coefficient between approximately 0.279 and 0.669). We chose the most common complaints from AKI patients and evaluated their change before and after SLEDDf. Chen and $\mathrm{Ku}$ [16] found physical symptom distress and quality of life negatively correlated. Among 25 items of physical distress, we chose subjective symptoms and perceptions: appetite, sleep, static activity limitation, chest pain, palpitation, and dyspnea. The first three items had 1-5 score, and the last three symptoms $1-3$, according to the degree of symptom improvement (a higher score signifying greater improvement). Children had to be conscious and able to answer simple questions. Rating was based on medical and nursing records.

\section{Components of SLEDD-f}

Treatment was performed with a Fresenius 5008 on-line hemodiafiltration system. Polysulfone high flux hemodiafilter, FX60 (membrane surface $1.4 \mathrm{~m}^{2}$ and priming volume $74 \mathrm{ml}$ ) and FX40 (membrane surface $0.6 \mathrm{~m}^{2}$ and priming volume $32 \mathrm{ml}$ ) were used for BW above and below $40 \mathrm{~kg}$ respectively. For operating parameters, blood flow rates were set at $5 \mathrm{ml} / \mathrm{kg} / \mathrm{min}$ for BW $20-40 \mathrm{~kg}$ or $200 \mathrm{ml} / \mathrm{min}$ for BW above $40 \mathrm{~kg}$, countercurrent dialysate flow to $260 \mathrm{ml} / \mathrm{min}$ and filtration rate to $35 \mathrm{ml} / \mathrm{kg} / \mathrm{h}$ in pre-dilution mode. According to blood flow (Qb) and filtration rate (Qf), total pre-dilution replacement fluid was calculated as $[(\mathrm{Qf} \times \mathrm{Qb}) /(\mathrm{Qb}-\mathrm{Qf})] \times 60 \times$ treatment duration (hours) . Treatment lasted $8-10 \mathrm{~h}$ daily. Constituent concentration of dialysate and replacement fluid were: $\left[\mathrm{Na}^{+}\right]: 138 \mathrm{mEq} / \mathrm{L}$, $\left[\mathrm{K}^{+}\right]: 2.0 \mathrm{mEq} / 1,\left[\mathrm{Cl}^{-}\right]: 109.5 \mathrm{mEq} / 1,\left[\mathrm{Mg}^{2+}\right]: 1.0 \mathrm{mEq} / 1$, $\left[\mathrm{Ca}^{2+}\right]: 3.0 \mathrm{mEq} / 1,\left[\mathrm{HCO}_{3}^{-}\right]: 32 \mathrm{mEq} / \mathrm{l}$. Anticoagulation infusion in the extracorporeal blood circuit was unfractionated heparin with a loading dose of 10-20 IU/kg and maintenance dose $5-10 \mathrm{IU} / \mathrm{kg} / \mathrm{h}$. For those with prolonged activated partial thromboplastin time (aPTT) $>75 \mathrm{~s}$, international normalized ratio $($ INR) $>2$, activated clotting time $(\mathrm{ACT})>275 \mathrm{~s}$, platelet count $<50,000 / \mu \mathrm{l}$, and/or clinical presentation or suspect bleeding diathesis, we lowered the heparin dose or held it steady. In most cases, we used aPTT as the parameter and 
adjusted the heparin dose. We checked aPTT at 0,3 , and $6 \mathrm{~h}$ from the arterial site: if aPTT $<35 \mathrm{~s}$ or below baseline, heparin $500 \mathrm{IU}$ bolus and add $200 \mathrm{IU} / \mathrm{h}$; if sPTT $>35 \mathrm{~s}$, but $<45 \mathrm{~s}$, add heparin $200 \mathrm{IU} / \mathrm{h}$; if aPTT $>45 \mathrm{~s}$ but $<55 \mathrm{~s}$, add heparin $100 \mathrm{IU} / \mathrm{h}$; if aPTT $>55 \mathrm{~s}$, but $<65 \mathrm{~s}$, keep heparin at maintenance dose; if aPTT $>65 \mathrm{~s}$ but $<75 \mathrm{~s}$, subtract heparin $50 \mathrm{IU} / \mathrm{h}$; if aPTT $>75 \mathrm{~s}$, hold heparin. If any of these parameters (aPTT, INR, ACT, platelet count) or clinical presentation of bleeding existed, such as gastric ulcer with bleeding or epistaxis, we held heparin or adjusted it to the lowest dose. The machine is able to auto-flush normal saline each hour to prevent tube clotting.

\section{Statistics}

All values in figures and tables are expressed as mean \pm standard error. Student's $t$ tests (unpaired, two-tailed) were used for intergroup comparison, with $p$ value $<0.05$ indicating statistical significance. Analysis was performed with SPSS/Windows software.

\section{Results}

\section{Patient characteristics}

From February 2010 to June 2011, 14 patients received a total of 60 SLEDD-f treatments. Mean age was 14.9 \pm 2.3 years, mean body weight was $54.4 \pm 23.3 \mathrm{~kg}$. Average PRISM III scores were $16.8 \pm 23.3$. Five patients had PRISM III scores under 10, another 9 over 10. Table 1 details the clinical characteristics.

Of the 3 ESRD patients, 1 girl with renal transplantation returned to dialysis owing to recurrent focal segmental glomerulosclerosis (FSGS) with progressive pulmonary edema and intolerance to IHD; 1 girl suffered from progressive generalized edema, hypertension and intolerance to IHD; and 1 boy with progressive FSGS to ESRD, cachexia, and intolerance to IHD, but the peritoneal dialysis tube was not implanted. Intolerance to IHD and poor ultrafiltration were indicators in these 3 ESRD patients.

Eleven patients had AKI: 2 with renal transplant had multi-organ dysfunction syndrome (MODS); 1 had a stem cell transplant with graft-versus-host disease (GVHD) and MODS; 1 with diabetic ketoacidosis and pulmonary edema; 2 with crescentic glomerulonephritis showed renal damage progression; 1 with a mediastinal yolk sac tumor suffered from cardiogenic shock, respiratory failure, and MODS; 1 had lupus nephritis superimposed influenza A infection complicated by acute respiratory distress syndrome (ARDS) and MODS; 2 girls with lupus nephritis had refractory nephrotic syndrome with pulmonary edema; another girl with lupus nephritis suffered from refractory nephrotic syndrome and septic shock with Klebsiella pneumonia complicated with MODS.

Thirteen patients had pulmonary edema; 5 had respiratory failure and needed positive airway pressure or intubation and mechanical ventilation. Six patients diagnosed with

Table 1 Clinical characteristics in patients receiving sustained low-efficiency daily diafiltration (SLEDD-f)

\begin{tabular}{|c|c|c|c|c|c|c|c|c|}
\hline Number & Diagnosis & $\begin{array}{l}\text { PRISM } \\
\text { score }\end{array}$ & $\begin{array}{l}\text { Number of } \\
\text { treatments }\end{array}$ & $\begin{array}{l}\text { Number of } \\
\text { pressors }\end{array}$ & $\begin{array}{l}\text { AKI or } \\
\text { ESRD }\end{array}$ & $\begin{array}{l}\text { Pulmonary } \\
\text { edema }\end{array}$ & MODS & $\begin{array}{l}\text { 28-day } \\
\text { survival }\end{array}$ \\
\hline 1 & $\begin{array}{l}\text { Methylmalonic acidemia, renal and liver transplantation, } \\
\text { shock }\end{array}$ & 30 & 4 & 3 & AKI & Yes & Yes & No \\
\hline 2 & Mediastinal yolk sac tumor, cardiogenic shock & 22 & 2 & 2 & AKI & Yes & Yes & Yes \\
\hline 3 & Lymphoma, stem cell transplantation, GVHD, shock & 26 & 2 & 3 & AKI & Yes & Yes & No \\
\hline 4 & ESRD, renal transplantation, recurrent FSGS & 11 & 3 & 0 & ESRD & Yes & No & Yes \\
\hline 5 & ESRD, intolerance to IHD & 9 & 2 & 0 & ESRD & Yes & No & Yes \\
\hline 6 & $\begin{array}{l}\text { SLE, lupus nephritis, refractory nephrotic syndrome, } \\
\text { intolerance to IHD }\end{array}$ & 9 & 11 & 0 & AKI & Yes & No & Yes \\
\hline 7 & $\begin{array}{l}\text { SLE, lupus nephritis, refractory nephrotic syndrome, } \\
\text { Klebsiella pneumonia septic shock }\end{array}$ & 35 & 3 & 3 & AKI & Yes & Yes & No \\
\hline 8 & Diabetic ketoacidosis & 10 & 4 & 0 & AKI & Yes & No & Yes \\
\hline 9 & ESRD, renal transplantation, chronic rejection, septic shock & 24 & 4 & 3 & AKI & Yes & Yes & No \\
\hline 10 & $\begin{array}{l}\text { SLE, lupus nephritis, influenza A infection with acute } \\
\text { respiratory distress syndrome }\end{array}$ & 31 & 7 & 1 & AKI & Yes & Yes & Yes \\
\hline 11 & SLE, lupus nephritis, refractory nephrotic syndrome & 4 & 3 & 0 & AKI & Yes & No & Yes \\
\hline 12 & Crescentic glomerulonephritis IgA nephropathy & 7 & 8 & 0 & AKI & Yes & No & Yes \\
\hline 13 & Crescentic glomerulonephritis & 7 & 3 & 0 & AKI & Yes & No & Yes \\
\hline 14 & FSGS progressing to ESRD, cachexia & 10 & 4 & 0 & ESRD & No & No & Yes \\
\hline
\end{tabular}

AKI: acute kidney injury; ESRD: end-stage renal disease; FSGS: focal segmental glomerulosclerosis; MODS: multi-organ dysfunction syndrome; GVHD: graft-versus-host disease; SLE: systemic lupus erythematosus; PRISM: pediatric risk of mortality; IHD: intermitent hemodialysis 
MODS all needed inotropic agents: 4 received three kinds of inotropic agents and died within 4 weeks.

For 7 critical patients with relative hemodynamic stability, sessions of IHD were performed; premature termination resulted in poor ultrafiltration due to chest tightness, angina, dizziness, tachycardia, and hypotension. They tolerated SLEDD-f well, with adequate ultrafiltration, subsiding pulmonary edema, and few complications. Quality of life improvements included better sleep, appetite, and static activity, all without discomfort.

Improvement in blood pressure control

Average treatment duration was $8.0 \pm 0.5 \mathrm{~h}$ and fluid removal per treatment was $2,390 \pm 103 \mathrm{ml}$. In patients with hypertension, mean sBP $153.5 \pm 9.4 \mathrm{mmHg}$ before SLEDD-f fell to $145.3 \pm$ $17.2 \mathrm{mmHg}(p<0.02)$ after treatment; on the other hand, for patients with hypotension, a mean sBP $87.0 \pm 3.5 \mathrm{mmHg}$ before SLEDD-f became $80.9 \pm 11.4 \mathrm{mmHg}$ during treatment $(p=$ 0.15 ; Fig. 1), revealing insignificant depression. Three episodes of intradialytic hypotension ( 3 out of $60,5.0 \%$ ) led to premature termination. There was no apparent increase in dose or de novo institution of inotropic agents during and after treatment.

Improvement of pulmonary edema and pulmonary hemorrhage

To evaluate correction of hemodilution, we recorded changes in hemoglobin $(\mathrm{Hb})$, hematocrit $(\mathrm{Hct})$, and their ratio $(\mathrm{Hct} /$ $\mathrm{Hb}$ ). Before SLEDD-f, mean $\mathrm{Hb}$, Hct, and $\mathrm{Hct} / \mathrm{Hb}$ ratio were $10.6 \pm 1.6 \mathrm{~g} / \mathrm{dl}, 30.5 \pm 5.4 \%$, and $2.83 \pm 0.15$. SLEDD-f changed these data to $11.6 \pm 2.2 \mathrm{~g} / \mathrm{dl}, 33.8 \pm 6.0 \%$ and $2.95 \pm$ 0.16 respectively (Fig. 2). A potential trend existed towards improvement (although not statistically significant), with no apparent intradialytic hemorrhage or blood consumption. Pulmonary edema (Fig. 3) improved after SLEDD-f therapy. A 14-year-old girl with active SLE and refractory nephrotic syndrome suffered from sudden onset of cyanosis, dyspnea, and hematemesis. Chest X-ray revealed a diffuse alveolar pattern, implying alveolar hemorrhage. SLEDD-f therapy and aggressive immunosuppressant treatment resulted in subsidence of pulmonary hemorrhage, and the ventilation and oxygenation improved gradually.

Improvement of hyperkalemia and metabolic acidosis

Hyperkalemia appeared in 5 patients (mean serum potassium $5.6 \pm 0.8 \mathrm{mEq} / \mathrm{l}$ before SLEDD-f) and was corrected to within the normal range $(4.3 \pm 0.7 \mathrm{mEq} / 1$ during and $4.1 \pm$ $0.7 \mathrm{mEq} / 1$ after SLEDD-f, $p<0.05$ ). Those with metabolic acidosis regained normal plasma levels $(7.27 \pm 0.16$ preSLEDD-f and $7.32 \pm 0.11$ post-SLEDD-f, $p<0.05$ ), low $\mathrm{HCO}_{3}$ returning to within a normal range $(20.3 \pm 5.7$ and $26.5 \pm 7.0 \mathrm{mEq} / 1$ respectively, $p<0.02$; Fig. 4 ). Sodium, calcium, magnesium and/or phosphate showed no significant change.

\section{Decreased inflammatory markers}

We checked the serum inflammatory markers adiponectin, interleukin 17A (IL-17A), and IL-6 from only 8 survivors. Before SLEDD-f, serum adiponectin levels were 3,835.0土 $1,011.7 \mathrm{pg} / \mathrm{ml}$, IL-17A levels $1,248.2 \pm 212.6 \mathrm{pg} / \mathrm{ml}$ and IL-6 levels $204.5 \pm 100.6 \mathrm{pg} / \mathrm{ml}$. After SLEDD-f, serum adiponectin levels fell significantly to $661.3 \pm 377.5 \mathrm{pg} / \mathrm{ml} \quad(p<$
Fig. 1 Changes in blood pressure (BP) in hypertensive (systolic $\mathrm{BP}>145 \mathrm{mmHg}$ ) and hypotensive (systolic $\mathrm{BP}<90 \mathrm{mmHg}$ ) patients before, during, and after sustained low-efficiency daily diafiltration (SLEDD-f) therapy. Boxes and bars represent the interquartile range and the median value respectively. The middle number represents the median value. In a hypotensive group, the comparison did not reach statistical significance
Systolic BP > 145mmHg

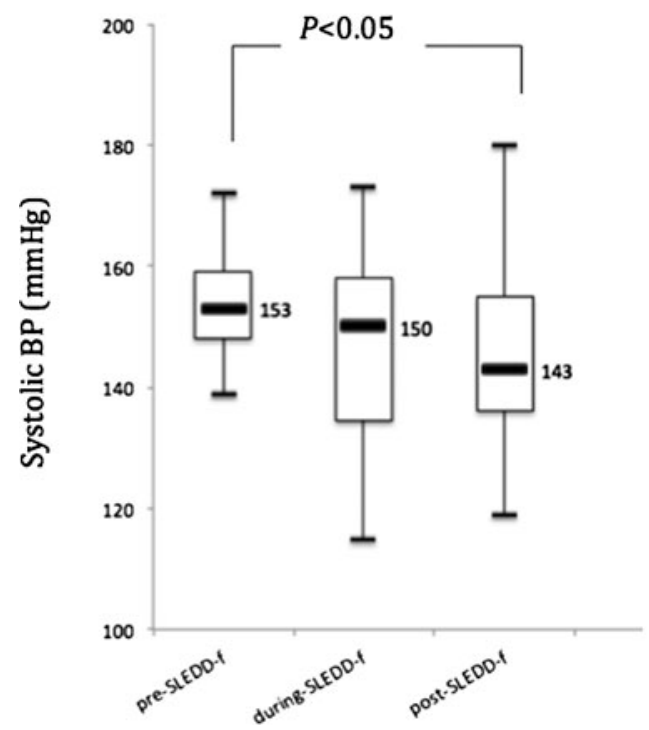

Systolic BP $<90 \mathrm{mmHg}$

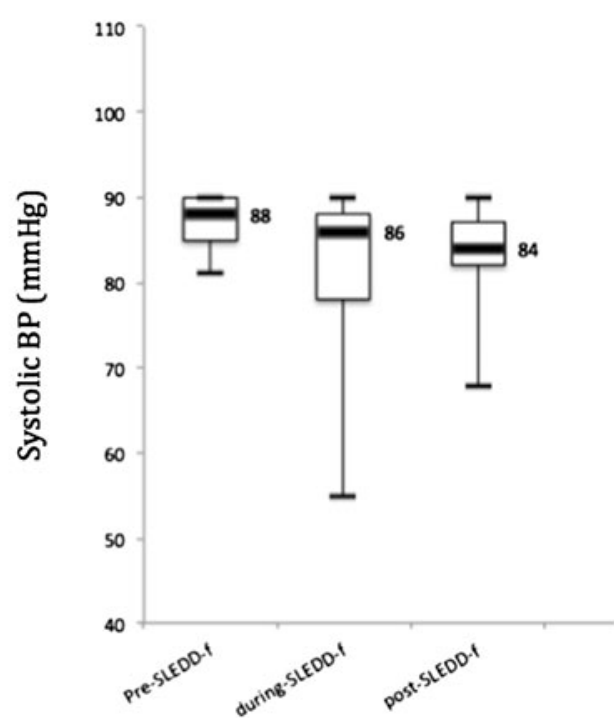


Fig. 2 Changes in

hemodilution before and after sustained low-efficiency daily diafiltration (SLEDD-f) therapy. Boxes and bars represent interquartile range and median value respectively. The middle number represents the median value. None of these comparisons reached statistical significance
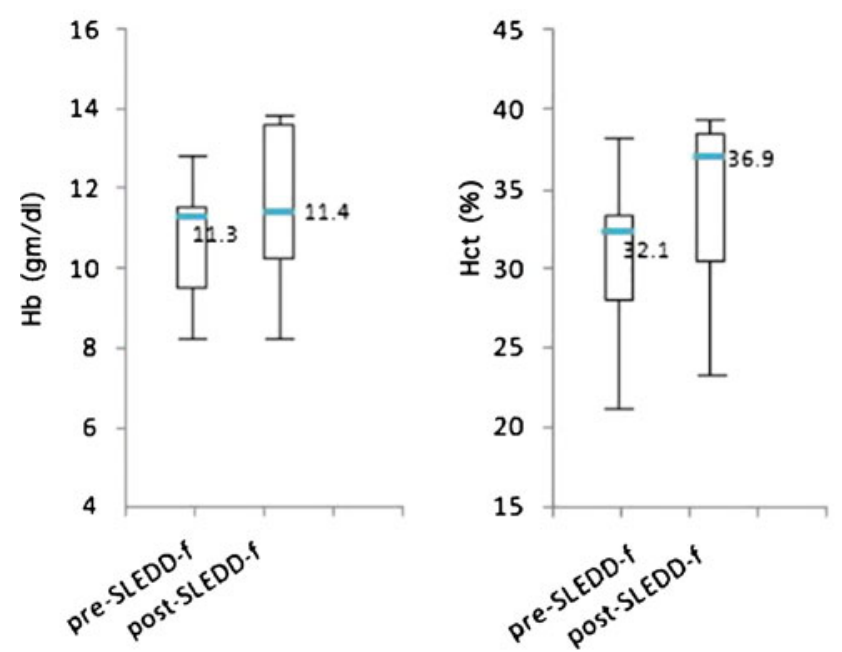

0.001), IL-17A to $10.4 \pm 7.6 \mathrm{pg} / \mathrm{ml}(p<0.001)$ and IL-6 levels to $61.9 \pm 25.7 \mathrm{pg} / \mathrm{ml}(p<0.001)$.

\section{Complication during SLEDD-f}

Heparin was prescribed in 46 out of 60 treatments $(76.6 \%)$, without bleeding complications. In 14 treatments without heparin, one episode of circuit clotting $(1 / 60,1.7 \%)$ occurred and led to premature termination.

\section{Mortality}

Four patients died; 28-day survival was 71.4\%. According to the PRISM III score, 5 patients with PRISM III score $<10$ had $100 \%$ survival; 9 with PRISM III score $>10$ had $55.6 \%$ survival. Four patients received renal (3 patients) or stem cell (1 patient) transplantation, and 3 died. A 17-year-old boy with methylmalonic acidemia (MMA) after liver and renal transplantation suffered from severe hemorrhagic peptic ulcer with hypovolemic shock, systemic cytomegalovirus
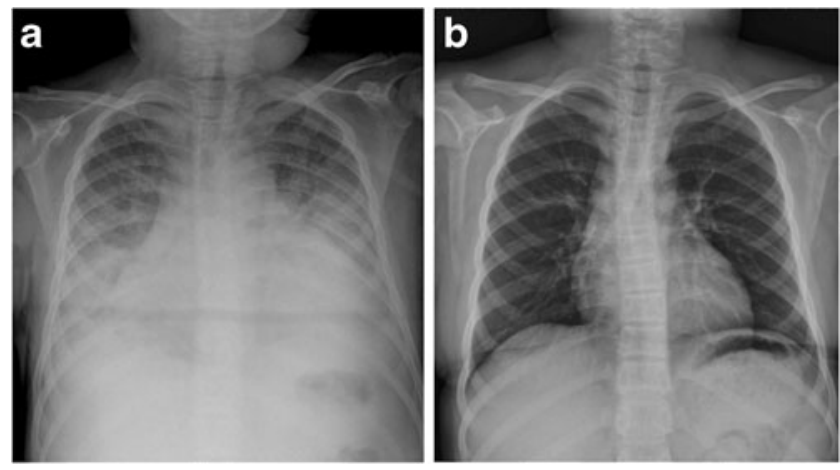

Fig. 3 Changes in pulmonary edema before and after sustained lowefficiency daily diafiltration (SLEDD-f) therapy. a Significant lung marking, blunting costophrenic angle, and cardiomegaly before SLEDD-f. b Condition improved after SLEDD-f therapy

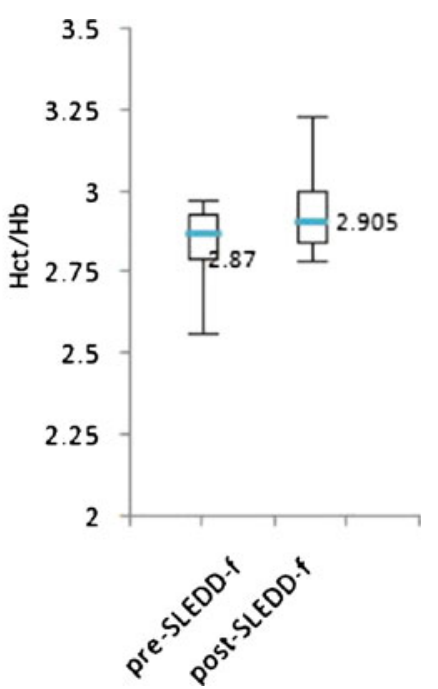

disease, Pneumocystis jiroveci pneumonia with respiratory failure and hepatorenal syndrome. A 13-year-old girl with FSGS progressing to ESRD after a renal transplant had an acute rejection, pneumonia with respiratory failure and septic shock. The other 17-year-old boy with lymphoma after stem cell transplantation suffered from graft-versus-host disease (GVHD), AKI, respiratory failure, and liver failure. One girl with renal transplantation survived, but returned to ESRD because of recurrent FSGS and acute rejection. A 14-year-old girl with SLE had refractory nephrotic syndrome and died of Klebsiella pneumonia-related septic shock. These 4 had MODS (Table 1).

Comparison of survivors and nonsurvivors (Table 2) shows similar age, BW, eGFR, and BUN before SLEDD-f. Nonsurvivors had a significantly higher PRISM III score, $\%$ FO, MODS, and vasopressor usage. Of 4 nonsurvivors, 1 boy received bone marrow transplantation, another had a concurrent liver and kidney transplant, while another had a renal transplant. All had high PRISM III scores, clinical fluid overload, and MODS.

Analysis of quality of life

In 34 SLEDD-f trials for 6 patients, quality of life analyses were performed. According to medical charts and nursing records, sleep quality, appetite, static activity, and objective symptoms (chest pain or tightness, palpitation, and dyspnea) scores improved after SLEDD-f (Fig. 5).

Cost analysis

Hemodiafilter and tubing for CVVH costs US\$235, versus about US\$69 for SLEDD-f. Because of the longer duration, CVVH needs larger amounts and more expensive replacement fluid (US\$70) than the dialysate needed for SLEDD-f (US\$8). The average cost of each SLEDD-f treatment was 
Fig. 4 Changes in serum potassium and metabolic acidosis before and after sustained low-efficiency daily diafiltration (SLEDD-f) therapy. Boxes and bars represent interquartile range and the median value respectively. The middle number represents the median value. Differences between preand post-SLEDD-f therapy were statistically significant

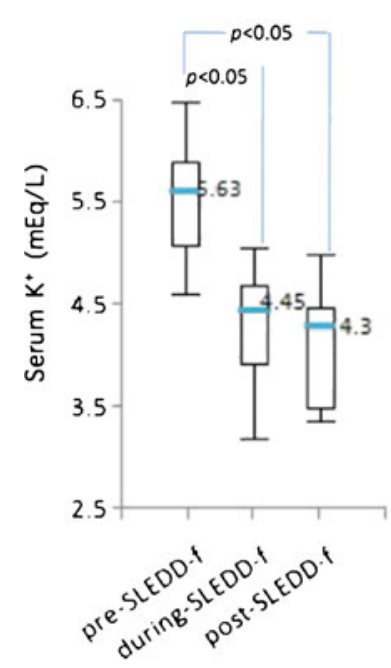

US\$77 per day, as opposed to CRRT with an average of US $\$ 305$. It is hard to calculate personnel fees under a different nation's insurance system. Given limited resources, it is important to select treatments with greater or equal efficacy and cheaper consumable materials.

\section{Discussion}

The present study is the first report of SLEDD-f treatment to analyze hemodynamic stability, volume control, acid-base, electrolyte correction, quality of life, and survival in critical children. SLEDD-f proves to be less costly than CVVH in the realm of consumable materials. Patients intolerant to IHD, while treated with SLEDD-f, enjoyed better efficacy, more stable hemodynamics and better quality of life. Further comparison will be needed to demonstrate these advantages.

In adults, controversy exists over superior survival after IHD or CRRT [17]. Differences in clinic, technique, and distribution of extracellular and intracellular fluid between populations make it unwise to apply CRRT adult data to
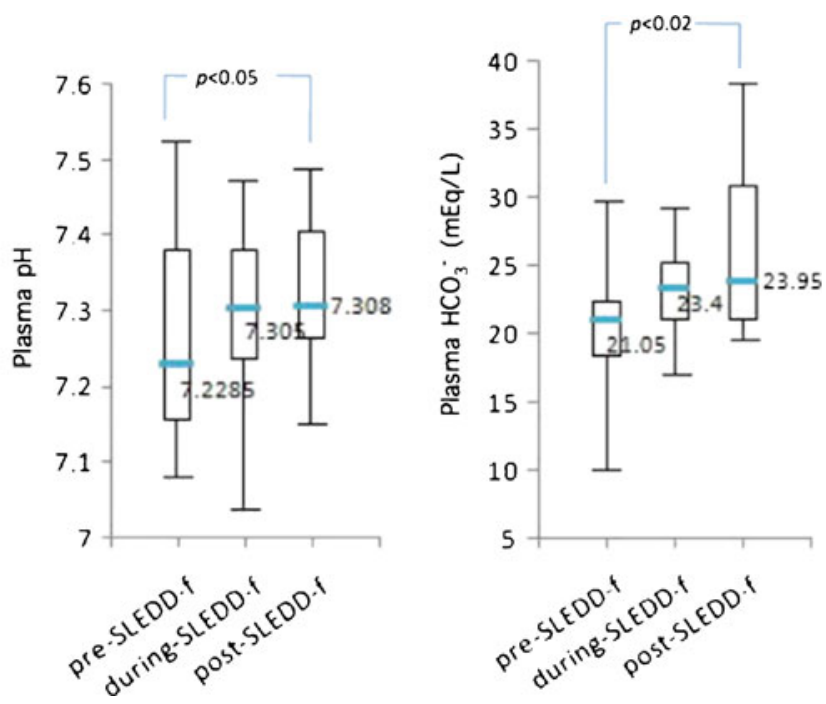

children. Recent studies [2, 18, 19] have suggested CRRT to be the preferred modality for critical children. Appropriate CRRT merits special consideration, given the range of body weight and composition of intra- and extracellular fluid. Owing to immature renal tubular function, metabolic acidosis and electrolyte disturbance develop more readily in children than in adults. During CRRT delivery, a substantial proportion of blood volume was pumped through the extracorporeal circuit. Children developed more complications with CRRT. It is difficult to establish catheterization with relatively larger caliber central venous or double lumen catheters; more accurate fluid control is needed, since the larger extracorporeal volume of the circuit may predispose to hypotension. In lower body weight patients, extracorporeal blood volume exceeds $10 \%$ of blood volume, exposing them to risks associated with hemodynamic instability [4] and adverse transfusion reaction: anaphylaxis, hemolysis, infection, lung injury, and GVHD [20].

Two major studies on pediatric CRRT [21, 22] revealed diffusion-based continuous veno-venous hemodiafiltration (CVVHDF) and hemodialysis (CVVHD) to be the favored
Table 2 Patients' characteristics by survival status

$\%$ FO: fluid overload \%; PRISM: Pediatric Risk of Mortality; SLEDD-f: Sustained low-efficiency daily diafiltration; MODS: multi-organ dysfunction syndrome; eGFR: estimated glomerular filtration rate given in $\mathrm{ml} / \mathrm{min} / 1.73 \mathrm{~m} 2$; BUN: blood urea nitrogen, $\mathrm{mg} / \mathrm{dl} . P<0.05$ represents a significant association between surviving and nonsurviving patients

\begin{tabular}{lllll}
\hline Variable & $\begin{array}{l}\text { All } \\
n=14\end{array}$ & $\begin{array}{l}\text { Survival } \\
n=10\end{array}$ & $\begin{array}{l}\text { Non-survival } \\
n=4\end{array}$ & $p$ value \\
\hline Age (years) & $14.9 \pm 2.3$ & $14.7 \pm 2.5$ & $15 \pm 2.4$ & 0.426 \\
Weight (kg) & $54.4 \pm 23.3$ & $57.1 \pm 25.9$ & $55.8 \pm 17.2$ & 0.463 \\
PRISM at SLEDD-f & $16.8 \pm 10.6$ & $12 \pm 8.2$ & $28.8 \pm 4.9$ & 0.0015 \\
\%FO before SLEDD-f & $4.7 \pm 3.0$ & $3.8 \pm 2.9$ & $7.1 \pm 1.8$ & 0.023 \\
Inotropes (number at SLEDD-f) & $1.1 \pm 1.4$ & $0.3 \pm 0.7$ & 3 & $<0.001$ \\
MODS & $42.9 \%$ & $20 \%$ & $100 \%$ & $<0.001$ \\
eGFR before SLEDD-f & $35.2 \pm 32.5$ & $33.3 \pm 31.6$ & $39.8 \pm 39.5$ & 0.375 \\
BUN before SLEDD-f & $93.9 \pm 66.6$ & $88.2 \pm 74.2$ & $108.2 \pm 48.2$ & 0.315 \\
Transplantation & 4 & 1 & 3 & 0.0045 \\
Shock & 4 & 1 & 3 & $<0.001$ \\
\hline
\end{tabular}




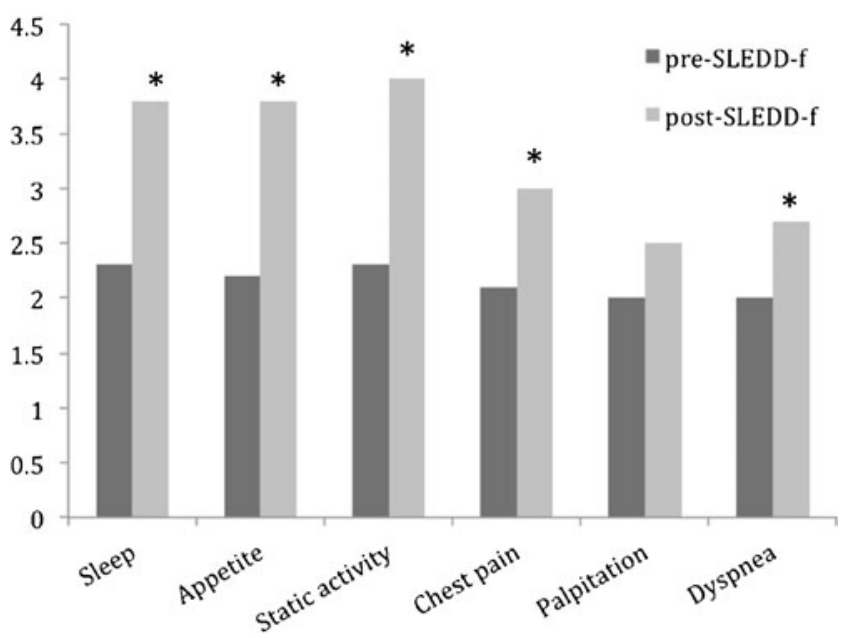

Fig. 5 Changes in quality of life before and after sustained low-efficiency daily diafiltration (SLEDD-f) therapy. Asterisk represents $p<0.05$

modalities (74\% and $78 \%)$. Better survival was noted among patients treated with CVVHD and CVVHDF than among those treated with CVVH [21]. Marshall et al. [7] showed that SLEDD-f afforded a greater dose of dialysis than IHD and could provide small solute clearance comparable to that from a CRRT regimen with substitution fluid rate of $35 \mathrm{ml} / \mathrm{kg} / \mathrm{h}$. Based on the theoretical data presented, increases in either Qf or treatment duration could be easily induced as part of routine SLEDD-f to afford a similar amount of convective clearance as CRRT. SLEDD-f is expected to have better patient outcome and wider clinical application.

Acute kidney injury is no isolated event, and it engenders distant organ injury to lungs, heart, liver, and brain via a mechanism involving neutrophil migration, higher cytokine concentration, and oxidative stress [23]. Understanding the mechanism behind AKI-induced distal organ injury is vital, as it may reveal new therapeutic targets. We found a significant decrease in serum adiponectin, IL-17A, and IL-6 level in survivors after SLEDD-f, a phenomenon that might represent an association between removing certain cytokines and AKI outcome, but this study is limited in terms of its small number and retrospective design.

Adiponectin, an adipokine, is produced almost exclusively by adipocytes and circulates in high concentrations in human plasma [24, 25]. Alteration in blood adiponectin concentrations has been linked to many human diseases in numerous cross-sectional and prospective studies. Adiponectin is markedly increased in patients with nephrotic syndrome; proteinuria is strongly related to circulating adiponectin in patients with nephrotic syndrome and nonnephrotic renal disease [26]. Investigation of critical illness [25] revealed an inverse correlation between adiponectin and inflammatory cytokines; whether this emanates from the disease process itself, or whether patients with lower levels of this hormone are more susceptible to critical illness is unknown. However, there were no data on the association among adiponection, AKI, diafiltration, and prognosis. Our study revealed decreased adiponectin levels after SLEDD-f in 8 survivors. The phenomenon might imply either SLEDD-f removal of adiponectin or represent a natural recovery from a critical condition. This limited retrospective study had neither control nor comparative groups; in future we aim to conduct better-designed research to investigate these possibilities.

IL-17A is a proinflammatory cytokine released by both T cells and innate immune cells, and plays a key role in both innate and adaptive immunity [27]. Convincing experimental evidence indicates that IL-17-producing T cells contribute to kidney injury in renal inflammatory diseases [28, 29]. In animal studies after ischemic or non-ischemic AKI, plasma TNF- $\alpha$, IL-17A, and IL-6 increased sharply, leading to small intestine and liver injury [30]. In critically ill patients, controversial results revealed that IL-17 might induce multiple organ dysfunctions [31-33]. In our study, high serum IL-17A decreased significantly after successful SLEDD-f treatment in 8 survivors. Changes in serum adiponectin, IL-17A, and IL-6 might indicate that SLEDD-f is able to remove certain inflammatory markers. However, incomplete data on the clearance of urea and creatinine limited the possibility of rating the efficacy of SLEDD-f in terms of depuration. Further research is needed in this area.

Pulmonary edema, acid-base disturbance and/or electrolyte imbalance were principal indications for renal replacement therapy. IHD is the most efficient modality for fluid, metabolic, and electrolyte control. Yet rapid fluid shifts are not well tolerated in complicated and unstable clinical conditions [4]. Such patients better tolerate CRRT hemodynamically; hemorrhage and/or electrolyte disturbance represent major complications [5]. Our 3 pulmonary edema patients who were intolerant to IHD adapted to SLEDD-f well, showing improved symptoms and quality of life.

Children tend to bleed more than adults [34, 35] during maturation of the hemostatic system. According to the literature regarding the complications of CRRT in critically ill children [5], 10\% on CRRT presented clinically significant hemorrhage, with no correlation between the presence of hemorrhage and age, weight, diagnosis or clinical severity at the start of CRRT. Though differences did not reach statistical significance, they indicated higher mortality in patients with rather than without hemorrhage. Heparin use requires careful adjustment to avoid either hemorrhage or circuit clotting. Hemorrhage in critically ill children with CRRT could arise from a number of factors: coagulation disorder, platelet dysfunction, altered tissue perfusion, CRRT itself, and anticoagulation. When our SLEDD-f patients had any clinical presentation of bleeding or suspected hemorrhagic diathesis, heparin was adjusted or held. No such bleeding complication appeared in our patients, but one episode of 
circuit clotting occurred at $3.5 \mathrm{~h}$ and led to premature termination in a patient with multi-organ involvement.

Hypotension is a key problem for critically ill children. Hypotension at CRRT connection is one of the most common CRRT-related complications [5]. After smooth connection, CRRT is advantageous for hemodynamically unstable patients as it need not be terminated because of hypotension, unlike IHD. All our patients had smooth connection, while three episodes of intra-dialytic hypotension occurred in shock cases. We tried our best to slow down blood flow, raise the inotropic dose, and cease ultrafiltration, yet slower blood flow, disseminated intravascular coagulation (DIC), and thrombosis resulted in tube clotting and discontinuation of therapy. The need to terminate therapy depended on RRT modality effects as well as clinical conditions. This is also common for CVVH, especially for unstable hemodynamic patients, in our experience. The small number of patients precluded us from determining the superiority of either SLEDD-f or CVVH.

Mortality in critically ill children requiring CRRT is reported to be between 35.6 and $57.0 \%$ [21, 22, 36-38]. Different diseases and demographic traits correlate with diverse mortality rates. In adults on CRRT, risk factors associated with mortality were age, greater clinical severity score, hemodynamics, sepsis, and respiratory failure. In a prior study by Symons et al., mortality rose with lower body weight $(<10 \mathrm{~kg})$, younger age $(<1$ year), higher PRISM II score $(>10)$, combined fluid overload, metabolic acidosis, and multi-organ involvement [22]. In the prospective pediatric continuous renal replacement therapy (ppCRRT) registry group, survival of patients with PRISM II score $<10$ was $55 \%$; for those with $>10,47 \%$ [22]. In our report of those treated with SLEDD-f, the percentages were $100 \%$ and $55.6 \%$ in patients with PRISM III score $<10$ and $>10$ respectively. Besides PRISM III score, other parameters, such as pre-RRT multiple organ failure, fluid overload, hemodynamic disturbance, and administration of cardioactive drugs can offer more reliable prognostic indicators. Further analysis of critically ill children with MODS receiving CRRT in the ppCRRT registry group [11] highlighted the PRISM score, central venous pressure (CVP), and the percentage of fluid overload $(\% \mathrm{FO})$ at $\mathrm{CRRT}$ initiation as being sharply lower for survivors versus nonsurvivors. Table 2 compares surviving and nonsurviving patients: nonsurvivors more frequently suffered from MODS and had higher PRISM scores, \%FO at ICU, and inotropic agent usage before SLEDD-f initiation. Patients requiring SLEDD-f for primary or predominant renal disease tallied lower PRISM scores and had 100\% survival. Early SLEDD$\mathrm{f}$ intervention before severity progresses and fluid overload increases may improve the patient survival rate and decrease morbidity. In ppCRRT [22], the survival rate in liver disease and/or transplant patients was lower than the overall rates. Among nonsurviving patients, 2 with renal and 1 with stem cell transplant suffered from shock and MODS, including respiratory failure, AKI, and liver failure. Transplantation and shock predisposed to a poor prognosis.

This report is limited by its retrospective design, small patient numbers, lack of control groups for diverse treatments, and the fact that there were no young patients weighing less than $20 \mathrm{~kg}$, who are usually reported to be at a higher risk of complications and death. With respect to quality of life, a further limitation was the fact that it was based on a retrospective review of medical and nursing records, not an ad-hoc questionnaire.

In conclusion, our pilot study showed that the advantages of SLEDD-f for critically ill children with renal injury included good hemodynamic tolerance, stable BP, well controlled fluid overload, good correction of fluid overload, acidosis, and electrolyte imbalance, lower cost, and good survival. These results need confirmation in a wider study comparing RRT modalities in such children.

Open Access This article is distributed under the terms of the Creative Commons Attribution License which permits any use, distribution, and reproduction in any medium, provided the original author(s) and the source are credited.

\section{References}

1. Vanholder R, Van Biesen W, Lameire N (2001) What is the renal replacement method of first choice for intensive care patients? J Am Soc Nephrol 12:S40-S43

2. Goldstein SL (2009) Overview of pediatric renal replacement therapy in acute kidney injury. Semin Dial 22:180-184

3. Strazdins V, Watson AR, Harvey B (2004) European Pediatric Peritoneal Dialysis Working Group. Renal replacement therapy for acute renal failure in children: European guidelines. Pediatr Nephrol 19:199-207

4. Walters S, Porter C, Brophy PD (2009) Dialysis and pediatric acute kidney injury: choice of renal support modality. Pediatr Nephrol 24:37-48

5. Santiago MJ, López-Herce J, Urbano J, Solana MJ, del Castillo J, Ballestero Y, Botrán M, Bellón JM (2009) Complications of continuous renal replacement therapy in critically ill children: a prospective observational evaluation study. Crit Care 13:R184

6. O'Reilly P, Tolwani A (2005) Renal replacement therapy III: IHD, CRRT, SLED. Crit Care Clin 21:367-378

7. Marshall MR, Ma T, Galler D, Rankin AP, Williams AB (2004) Sustained low-efficiency daily diafiltration (SLEDD-f) for critically ill patients requiring renal replacement therapy: towards an adequate therapy. Nephrol Dial Transplant 19:877-884

8. Holt BG, White JJ, Kuthiala A, Fall P, Szerlip HM (2008) Sustained low-efficiency daily dialysis with hemofiltration for acute kidney injury in the presence of sepsis. Clin Nephrol 69:40-46

9. Weng KP, Hsieh KS, Hung AH, Lin CC (2002) Oscillometric ambulatory blood pressure values in healthy children. Acta Paediatr Taiwan 43:15-20

10. Akcan-Arikan A, Zappitelli M, Loftis LL, Wasburn KK, Jefferson LS, Goldstein SL (2007) Modified RIFLE criteria in critically ill children with acute kidney injury. Kidney Int 71:1028-1035 
11. Goldstein SL, Somers MJ, Baum MA, Symons JM, Brophy PD, Blowey D, Bunchman TE, Baker C, Mottes T, McAfee N, Barnett J, Morrison G, Rogers K, Fortenberry JD (2005) Pediatric patients with multi-organ dysfunction syndrome receiving continuous renal replacement therapy. Kidney Int 67:653-658

12. Goldstein SL, Currier H, Cd G, Cosio CC, Brewer ED, Sachdeva R (2001) Outcome in children receiving continuous venovenous hemofiltration. Pediatrics 107:1309-1312

13. Parfrey PS, Vavasour H, Bullock M, Henery S, Harnett JD, Gault MH (1989) Development of a health questionnaire specific for end-stage renal disease. Nephron 52:20-28

14. Ferrans CE, Powers MJ (1985) Quality of life index: development and psychometric properties. ANS Adv Nurs Sci 8:15-24

15. Yao KP (2002) Development and applications of the WHOQOLTaiwan version. Formosan Journal of Medicine 16:193-200

16. Chen ML, Ku NP (1998) Factors associated with quality of life among patients on hemodialysis. Nurs Res 6:393-404

17. Cho KC, Himmelfarb J, Paganini E, Ikizler TA, Soroko SH, Mehta RL, Chertow GM (2006) Survival by dialysis modality in critically ill patients with acute kidney injury. J Am Soc Nephrol 17:3132-3138

18. Warady BA, Bunchman T (2000) Dialysis therapy for children with acute renal failure: survey results. Pediatr Nephrol 15:11-13

19. Brophy PD (2008) Renal supportive therapy for pediatric acute kidney injury in the setting of multiorgan dysfunction syndrome/ sepsis. Semin Nephrol 28:457-469

20. Kuriyan M, Carson JL (2004) Blood transfusion risks in the intensive care unit. Crit Care Clin 20:237-253

21. Santiago MJ, López-Herce J, Urbano J, Solana MJ, del Castillo J, Ballestero Y, Botrán M, Bellón JM (2010) Clinical course and mortality risk factors in critically ill children requiring continuous renal replacement therapy. Intensive Care Med 36:843-849

22. Symons JM, Chua AN, Somers MJ, Baum MA, Bunchman TE, Benfield MR, Brophy PD, Blowey D, Fortenberry JD, Chand D, Flores FX, Hackbarth R, Alexander SR, Mahan J, McBryde KD, Goldstein SL (2007) Demographic characteristics of pediatric continuous renal replacement therapy: a report of the prospective pediatric continuous renal replacement therapy registry. Clin J Am Soc Nephrol 2:732-738

23. Yap SC, Lee HT (2012) Acute kidney injury and extrarenal organ dysfunction: new concepts and experimental evidence. Anesthesiology $116: 1-10$

24. Ouchi N, Kihara S, Arita Y, Maeda K, Kuriyama H, Okamoto Y, Hotta K, Nishida M, Takahashi M, Nakamura T, Yamashita S, Funahashi T, Matsuzawa Y (1999) Novel modulator for endothelial adhesion molecules: adipocyte-derived plasma protein adiponectin. Circulation 100:2473-2476
25. Robinson K, Prins J, Venkatesh B (2011) Clinical review: adiponectin biology and its role in inflammation and critical illness. Crit Care 20:221

26. Zoccali C, Mallamaci F, Panuccio V, Tripepi G, Cutrupi S, Parlongo S, Catalano F, Tanaka S, Ouchi N, Kihara S, Funahashi T, Matsuzawa Y (2003) Adiponectin is markedly increased in patients with nephrotic syndrome and is related to metabolic risk factors. Kidney Int Suppl 84:S98-102

27. Cua DJ, Tato CM (2010) Innate IL-17-producing cells: the sentinels of the immune system. Nat Rev Immunol 10:479-489

28. Turner JE, Paust HJ, Steinmetz OM, Panzer U (2010) The Th17 immune response in renal inflammation. Kidney Int 77:1070-1075

29. Ooi JD, Kitching AR, Holdsworth SR (2010) Review: T helper 17 cells: their role in glomerulonephritis. Nephrology (Carlton) 15:513-521

30. Li L, Huang L, Vergis AL, Ye H, Bajwa A, Narayan V, Strieter RM, Rosin DL, Okusa MD (2010) IL-17 produced by neutrophils regulates IFN-gamma-mediated neutrophil migration in mouse kidney ischemic-reperfusion injury. J Clin Invest 120:331-342

31. Park SW, Kim M, Brown KM, D'Agati VD, Lee HT (2011) Paneth cell-derived interleukin-17A causes multiorgan dysfunction after hepatic ischemia and reperfusion injury. Hepatology 53:1662-1675

32. van de Veerdonk FL, Kullberg BJ, Verschueren IC, Hendriks T, van der Meer JW, Joosten LA, Netea MG (2010) Differential effects of IL-17 pathway in disseminated candidiasis and zymosan-induced multiple organ failure. Shock 34:407-411

33. Bozza FA, Salluh JI, Japiassu AM, Soares M, Assis EF, Gomes RN, Bozza MT, Castro-Faria-Neto HC, Bozza PT (2007) Cytokine profiles as markers of disease severity in sepsis: a multiplex analysis. Crit Care 11:R49

34. Andrew M, Paes B, Johnston M (1990) Development of the hemostatic system in the neonate and young infant. Am J Pediatr Hematol Oncol 12:95-104

35. Andrew M, Vegh P, Johnston M, Bowker J, Ofosu F, Mitchell L (1992) Maturation of the hemostatic system during childhood. Blood 80:1998-2005

36. Pichler G, Rödl S, Mache C, Trop M, Ring E, Zobel G (2007) Two decades' experience of renal replacement therapy in paediatric patients with acute renal failure. Eur J Pediatr 166:139-144

37. Foland JA, Fortenberry JD, Warshaw BL, Pettignano R, Merritt RK, Heard ML, Rogers K, Reid C, Tanner AJ, Easley KA (2004) Fluid overload before continuous hemofiltration and survival in critically ill children: a retrospective analysis. Crit Care Med 32:1771-1776

38. Symons JM, Brophy PD, Gregory MJ, McAfee N, Somers MJ, Bunchman TE, Goldstein SL (2003) Continuous renal replacement therapy in children up to $10 \mathrm{~kg}$. Am J Kidney Dis 41:984-989 